\title{
Coronavirus Disease 2019 (COVID-19) Health Strategy for Dental and Oral Medicine
}

\author{
M Sidqui, A EL Aouame* and F El Quars \\ Faculty of Dental Medicine of Casablanca, Abu Al Alaa Zahar Street, mersultan, Casablanca, Morocco
}

Submission: September 05, 2020; Published: September 24, 2020

*Corresponding author: A EL Aouame, faculty of Dental Medicine of Casablanca, Abu Al Alaa Zahar Street, mersultan, Casablanca, Morocco

\begin{abstract}
Covid-19 is an infectious viral pathology caused by the seventh strain of coronaviruses called SARS-COV-2. (Severe acute respiratory syndrome). It has been declared a pandemic by the World Health Organization with a high mortality rate of up to $8 \%$. It has symptoms comparable to those of seasonal flu, although it is more contagious than this last. Human-to-human transmission of SARS-CoV-2 mainly occurs through the respiratory tract by the inhalation of infectious droplets or aerosols emitted by an infected person or through hand-carrying. Taking this into account and given the nature of aerosolizing dental care in the majority of cases, dental surgeons are among the health professionals most exposed to COVID-19. This requires very rigorous protection measures, from the closure of the office and the remote management of oral emergencies, to the implementation of very strict protocol for the individual protection of all medical staff of the dental clinic. All of this is in the aim of keeping the role of the dental office as a care provider, and not a source of disease transmission.
\end{abstract}

Keywords: COVID-19; Health strategy; Dental-oral medicine

Abbreviations: WHO: World Health Organization; ECDE: European Center for Disease Control and Prevention; PPE: personal protective equipment; HAS: hydro alcoholic solution; NSAIDs: nonsteroidal anti-inflammatory drugs

\section{Introduction}

Since November 17, 2019, an epidemic of pneumonia of uncertain etiology has appeared in Wuhan, China. There have been numerous reports concerning a living animal and the seafood market, claiming that the pathogens have been transferred from animals to humans, rapidly evolving into interhuman transmission. The pathogen was classified as a new corona virus 2019 (2019-nCoV) and the disease was named Corona Virus Disease 2019 (COVID-19) [1]. As of March 30, 2020, according to the World Health Organization (WHO), 2019-nCoV involved 201 countries among which the most infected countries are presented in Table 1 [2]. This virus caused a mortality rate of $2 \%$ and a reproduction index (R0) of 1.4-5.5 [2].

Table 1: Confirmed cases of COVID-19 statistics as of March 30, 2020

[2].

\begin{tabular}{|c|c|c|}
\hline Country & Total cases & Total deaths \\
\hline World & 693,282 & 33,106 \\
\hline USA & 122,653 & 2,112 \\
\hline Italy & 97,689 & 10,781 \\
\hline China & 82,447 & 3,310 \\
\hline Spain & 78,797 & 6,528 \\
\hline
\end{tabular}

SARS-CoV-2, the virus responsible for COVID-19 (Corona Virus Disease 2019) is a new coronavirus, it is enveloped (like the Virus Herpes simplex for example). Coronaviruses belong to the family of Corona viridae, including large single stranded RNAs more like genome. They are divided into four groups: $\alpha$ coronavirus, $\beta$ coronavirus, $\gamma$ coronavirus and $\delta$ coronavirus. A coronavirus and $ß$ coronavirus primarily infect the respiratory, gastrointestinal and central nervous systems of humans and mammals, while $y$ coronavirus and $\delta$ coronavirus primarily target birds [3-6]. The

SARS-CoV nucleocapsid $\mathrm{N}$ protein contains a sequence rich in basic amino acids which is absent in all other known coronaviruses and which could be a signal for nuclear translocation [7]. To date, there is no vaccine or specific antiviral treatment against SARS-CoV-2. Coronaviruses survive for up to 3 hours on dry inert surfaces and up to 6 days in a humid environment. Transmission by hand from the environment is therefore possible.

Human coronaviruses such as SARS-CoV and MERS-CoV can be effectively inactivated by surface disinfection procedures with $62-71 \%$ ethanol, $0.5 \%$ hydrogen peroxide or $0.1 \%$ hypochlorite of sodium in 1 minute. We can expect similar efficacy on SARS-CoV-2 [8-12]. Covid 19 is an infectious viral pathology caused by the 
seventh strain of coronaviruses called SARS-COV-2. (Severe acute respiratory syndrome). It has been declared a pandemic by the World Health Organization with a high mortality rate of up to $8 \%$. The virulence of the virus lies in its perpetual mutation. In total, the researchers identified 33 mutations in the genome, of which 19 are still unknown. COVID-19 is far more contagious than the seasonal flu virus. The COVID-19 incubation period generally lasts 3 to 7 days, most often 5 days, with a maximum of 14 days [13]. According to the WHO, the virus has reached 4.44 million cases since its appearance on May 15, 1.59 million cures and 3 to $2 \mathrm{~K}$ of deaths. A total of 6623 cases of COVID-19 have been registered in Morocco up to the same date, including 3380 cases cured and 190 deaths. As things stand, there is no vaccine to prevent the disease. One study reported that dentists and anesthetists are the highest risk professionals. Protective measures to prevent the spread of the virus as well as the protection of our patients and caregivers must be put in place [7]. The purpose of this article is to focus on the voices of virus contamination, the risks involved as well as on the means of prevention within the dental office.

\section{Natural history of the disease}

SARS-CoV2 is transmitted very efficiently by air. The median incubation period is 5 days but may be shorter (2-3 days). At least half of the carriers are asymptomatic or have brief symptoms 1 to a few days). On the other hand, the median carrying time is 14 days, and seems longer in more affected patients (median of 20 days in hospitalized patients). The virus remains present during the cytokine discharge phase and patients with a fatal evolution most often remain carriers of the virus at the time of death. This argues in favor of continuing antiviral treatment in patients with ARDS, even if the effectiveness of the antiviral treatments currently available seems rather limited. A worsening of respiratory symptoms with pneumonia, see ARDS develops towards the end of the first week in some of the patients who will have an unfavorable course [1,3-5].

\section{What is nCOVID- 19 or SARS- Cov 2?}

This virus belongs to the family of Coronaviridae which contains a large number of viruses, considered mainly as agents responsible for colds. This family is characterized by the presence of spicules made up of the surface protein S, giving a crown appearance visible in an electron microscope (hence their name). The SARS-Cov 2 genome is a non-segmented linear RNA molecule (very high mutation rate) of positive polarity, which allows it to replicate quickly inside cells and spread between people [14].

\section{How do you get Coronavirus?}

The usual gates are the mucous membranes. Thus, the respiratory mucosa (the nose, the mouth) and the mucosa of the digestive tract constitute the most common route of entry for microorganisms. The dermal route can also be a site of contamination, that is to say by contact or after break-in of the skin by an injury, a needle, or even a surgical intervention. Large epidemics have been able to follow each of these modes of entry. Respiratory epidemics, which are particularly dangerous since they are made from Man to Man by coughing and infection of the respiratory tree, and which can quickly cause pandemics affecting several million people. For inter-human diseases, the microorganism must find a way out of the body, to be able to contaminate another human being and thus weave a chain of infections. The exit routes are comparable to the entry routes. Coughing helps to germinate germs, so people with an infectious cough are contagious. Germs can also get out through the digestive tract, possibly contaminating the drinking water or the hands of the infected person. This transmission mechanism, called fecal peril, is transmitted through the hands, drink and food. The genital tract allows venereal transmission. Finally, the cutaneous route allows infections, on the one hand due to eruptive diseases associated with the presence of skin lesions, on the other by transcutaneous route $[15,16]$.

To summarize the transmission of the virus is done:

i. By droplets sprayed when an infected person coughs or sneezes (main mode of transmission).

ii. By touching your mouth, eyes or nose after being in contact with a contaminated surface.

\section{Can you get COVID-19 from someone who has no symptoms?}

a) The risk is very low. However, COVID-19 can be contracted from someone who, for example, has only a mild cough (early stages of the disease) but who does not feel sick.

b) The average duration of incubation is 2 to 5 days in general but can extend up to 14 days (the time between exposure to the virus and the manifestation of the first symptoms.

i. During this period, the subject can be contagious.

ii. From the end of the incubation period, High viral load $[17,18]$.

\section{What are the symptoms?}

a) Symptoms therefore comparable to those of the seasonal flu or a severe cold

b) Some people, although infected, have no symptoms and feel good.

c) In the most severe cases, infection can lead to:

$\begin{aligned} \text { i. } & \text { + Fever } \\ \text { ii. } & \text { + Respiratory dyspnea } \\ \text { iii. } & \text { + Pneumonia } \\ \text { iv. } & \text { + Kidney failure }[15,16] .\end{aligned}$




\section{What exactly do we die from?}

It is a pulmonary infection which leads to serious respiratory insufficiency which decompensates, the patient can be reached on an acute renal failure, even of a multi visceral failure which can lead to death. The Chinese Center for Disease Control and Prevention has published a study of 72,314 confirmed, suspect, clinically diagnosed and asymptomatic cases of viral pneumonia. It is the largest since the start of the epidemic at the moment [1719].

\section{Population at risk?}

The main risk factors for developing more severe forms of Covid-19 known are:

$\begin{aligned} \text { i. } & \text { Advanced age }(>65 \text { years) } \\ \text { ii. } & \text { Chronic respiratory diseases } \\ \text { iii. } & \text { Vascular diseases (including poorly controlled }\end{aligned}$ hypertension)

\section{iv. Diabetes}

v. The immune deficiency (organ transplant, HIV, treatment. Immunosuppressant)

vi. Progressive cancer

vii. Other: morbid obesity; cirrhosis, advanced renal failure, pregnancy.

However, younger patients may also experience symptoms of serious illnesses requiring intensive care therapies. Men are more threatened than women by a fatal outcome $(2.8 \%$ against $1.7 \%)$ [17-20].

\section{The diagnosis?}

The diagnosis of COVID-19 infection is made on the basis of:

a) Epidemiological arguments: Concept of stay in the virus circulation zone in less than 14 days, or direct contact with an infected person.

\section{b) Clinical argument}

\section{c) Radiological argument}

i. Analysis has shown that 2019-nCoV generally manifests on CT with a bilateral frosted glass and consolidating pulmonary opacities

ii. Nodular opacities and a peripheral distribution of the disease can be additional characteristics useful for early diagnosis.

\section{Biological argument or virological diagnosis:}

Detection of the virus in samples and its characterization according to two approaches:

i. Direct diagnosis: Highlighting the virus itself and / or one of its constituents. These are molecular biology techniques using a specific test (RT-PCR) for the diagnosis of Sars Cov 2 infections by the detection of the genes: $\mathrm{E}$ and RdRp.

ii. Indirect diagnosis: Demonstration of the antibodies synthesized following a viral infection (host response to infection).

The nature of the samples to be taken (depending on the predominant symptomatology)

i. Parenchymal involvement: Samples of the lower respiratory tract (sputum, LBA, Tracheal Aspiration).

ii. High predominant symptoms (cough, angina) + Upper respiratory tract samples (nasopharyngeal swab, nasal aspiration).

iii. Viremia has been demonstrated in some patients: Blood.

\section{Methods of Direct Debits}

\section{a) Adult:}

i. Samples of the lower respiratory tract can be obtained during coughing, provoked sputum or by tracheal suction (2 to 3 $\mathrm{ml}$ )
ii. $\quad 2$ to $3 \mathrm{ml}$ nasal suction
iii. Nasopharyngeal swab.

In a sterile, watertight tube with a screw cap or in a dry sterile container.

\section{b) Child <6 years:}

i. Sputum collection: very difficult

ii. A respiratory physiotherapy session followed immediately by nasopharyngeal aspiration: provoked sputum $[15,17]$.

\section{How to protect yourself?}

Wash your hands frequently and thoroughly with a hydro alcoholic solution or with water and soap to kill the virus if it is present on your hands. The World Health Organization (WHO) recommends a very specific protection technique. In case of fever, cough and shortness of breath, stay at home, if necessary, consult a doctor after calling it. He will be able to quickly direct you to the most suitable healthcare establishment. It will also protect you and prevent the spread of viruses and other infectious agents $[17,18,21,22]$.

\section{Should we wear a mask?}

If you are not sick, there is no reason to wear a mask, it is not recommended at all. On the other hand, if you have symptoms, if you cough, if you are not very well and you want above all to protect others, you can actually put on the surgical mask.

\section{Transmission modes}

The virus is transmitted directly by spraying contaminated droplets during a cough or sneeze, or indirectly by contact with an 
inert contaminated surface. This makes the dental office a potential vector for the viral transmission of SARS-COV-2 $[8,10,20]$.

Human-to-human transmission of SARS-CoV-2 occurs by respiratory or handlining:

a) Respiratory tract: Inhalation of infectious droplets or aerosols emitted during sneezing, coughing or talking by the patient or an asymptomatic carrier, close contact with an infected person is necessary to transmit Covid 19: same place of life, direct contact within three feet of a cough, sneeze, or chat in the absence of protective measures.

b) Handling: Hand contact with surfaces freshly contaminated with infectious droplets and then with the face. In fact, the mouth, nose or eyes are possible entry points for the virus into the body $[15,18,22]$.

\section{Survival of the virus on different surfaces}

Currently, only one study reports this information on SARSCov-2 under controlled laboratory conditions (temperature between 21 and $23^{\circ} \mathrm{C}$; air humidity $65 \%$ for the test of aerosols and $40 \%$ for the test of surfaces). The estimated half-life of the virus (time for halving the amount of virus) in aerosols would be 1.1 hours. Remember that aerosols are defined as very fine particles suspended in the air and that they cannot be compared to the droplets created by a person who sneezes, coughs or talks because they are much more volatile. The half-life of the virus on inert surfaces is reported to be 0.8 hours for wood, 3.5 hours for cardboard, 5.6 hours for steel and 6.8 hours for plastic. The virus could be detected in aerosols after three hours, up to 4 hours on wood, up to 24 hours on cardboard and two to 3 days on plastic and steel. However, it is not known until when the levels of virus observed remain high enough for there to be a risk of infection [21].

\section{Routes of contamination}

\section{Spread of the virus}

Person-to-person spread is the primary mode of transmission of SARS-Cov-2. It takes place mainly through droplets produced when coughing, sneezing or talking. A person can become infected if these droplets come into direct contact with their mucous membranes or if they touch an infected surface and then touch their eyes, nose or mouth. Since the virus can also be found in stool and conjunctiva, these modes of transmission are not excluded, but probably remain rare. For the medical sector, smear or aerosol infections (microdroplets less than 5 micrometers which may appear during certain procedures such as dental procedures, bronchoscopy and certain surgical techniques) are not excluded either, but we currently do not no evidence that they exist. Finally, scientists have not yet been able to determine whether mother-tochild transmission is possible during pregnancy. To our knowledge, none of the infants evaluated at birth has so far been positive for the Covid-19 reference test (RT-PCR based on the search for the virus genome). Some, however, had antibodies that could have passed the placenta barrier if the mother became infected during her pregnancy [15,17-19].

\section{Contagiousness}

A spike protein located on the surface of the virus is believed to be responsible for the rapid transmission of the virus. This allows the virus to attach to a cell to release its RNA and infect it. It is more easily cleaved by cells in the human body than other viruses in the same family. The average number of individuals that a person with SARS-Cov-2 can infect (basic reproduction rate of the virus, R0) would reach values between 1.4 and 2.5 according to the World Health Organization. However, studies report estimates of 1.4 to 6.5 . If the R0 of SARS-Cov-2 seems to vary as much from one publication to another, it is that its estimate is based on more or less complex mathematical models. These models consider the number of infected people (whom we never know exactly), likely to be infected or exposed, without symptoms, withdrawn (death and recovery) and sometimes many other parameters. It should also be considered in this interpretation of $\mathrm{R} 0$ that the barrier measures act on the contact rate and the probability of infection and therefore constantly modify it. A person is potentially contagious as soon as the viral load (quantity of the virus present in the body) becomes significant, even before the onset of symptoms. Transmission by subjects carrying the virus without symptoms is also possible and has been described several times. According to current information, the viral load of these people is similar to that of patients with symptoms. Excretion of the virus from the pharynx would be very high during the first week of symptoms (7X108 copies of RNA per throat sample). The appearance of antibodies (seroconversion) would be detectable 6 to 12 days after the onset of symptoms without observing a rapid decline in viral load. The latter could be detected up to 20 days (between 17 and 24 days for $50 \%$ of patients) after the onset of symptoms with a reported case of 37 days $[15,17,18,23]$.

\section{Vectors of contamination}

The common routes of transmission of new coronaviruses include direct transmission, which is the salivary voice and the airborne voice (coughing, sneezing and inhalation of droplets) and indirect or contact transmission (oral, nasal and with the ocular mucous membranes). The danger of Covid-19 transmission is due to the contagious risk present even in asymptomatic patients or in the incubation period [24].

\section{a) Air}

Based on the available evidence, air diffusion is not one of the main routes of transmission. The main causes of SARSCoV-2 are related to the bio-aerosols released into the air flow. The predominant mode of transmission in the initial phase of the epidemic appears to be the respiratory tract with "droplet" type transmission. This is supported by the high viral loads in the respiratory secretions shown by Drosten. The possibility 
of transmitting aerosols with the ability to move up to 6 meters in air has also been reported in the internal environment of ophthalmologists. As a result, HEPA filters were used for ventilation. However, atmospheric emissions for SARS-CoV-2 have not yet been reported. According to the available evidence, it is not confirmed that air can be one of the main causes of transmission. The possibility of air stability for SARS-CoV-2, as well as transmission through facial hair SARS-CoV-2 were also discussed [25].

\section{b) Saliva}

The salivary droplets emitted during sneezing, coughing, or speaking are a real transmission factor for Covid-19. Covid-19 can be transmitted through saliva directly or indirectly, even in patients with no cough or other respiratory symptoms. Saliva samples have a high sensitivity and specificity in the detection of respiratory viruses compared to those of the nasopharyngeal junction. It has also been shown that the use of saliva in the detection of coronaviruses reduces the time and costs associated with collecting samples [26]. More studies are needed to assess the potential diagnosis of Covid-19 in saliva and its impact on the transmission of this virus, which is essential for developing rapid diagnostic and prevention tests [27]. Saliva offers many advantages as a diagnostic fluid because it is easy to collect, store and contains very good DNA. Thus, saliva can be an ideal alternative for the blood. Recently, researchers from RUCDR Infinite Biologics at Rutgers University reported that saliva is an effective means for the detection of COVID-19 compared to nasopharyngeal or oropharyngeal samples. According to them, the use of saliva to extract viral RNA was in fact a reliable source for the detection of COVID-19 [27].

\section{c) Contact surfaces}

SARS-CoV can persist on surfaces such as metal, glass or plastic for up to a few days $[28,29]$. The half-life of the virus on inert surfaces is reported to be 0.8 hours for wood, 3.5 hours for cardboard, 5.6 hours for steel and 6.8 hours for plastic. It also remains in aerosols beyond three hours, up to 4 hours on wood, up to 24 hours on cardboard and two to 3 days on plastic and steel.

A study relating to the comparison of SARS-CoV-1 to SARSCoV-2 in terms of survival on different surfaces has shown that the latter has the capacity to remain alive in aerosols throughout the experiment which lasted 3 hours, with a reduction in viral titer from 103.5 to 102.7 TCID50 per liter of air [18]. This reduction was similar to that observed with SARS-CoV-1, from 104.3 to 103.5 TCID50 per milliliter. SARS-CoV-2 was more stable on plastic and stainless steel than on copper and cardboard and was able to stay alive up to 72 hours after application on these surfaces, although its viral titer was considerably reduced (from 103.7 to 100.6 TCID50 per milliliter of medium after 72 hours on plastic and from 103.7 to 100.6 TCID50 per milliliter after 48 hours on stainless steel). This study also reported that on copper, no viable SARS-
CoV-2 was detected after 4 hours and no viable SARS-CoV- 1 was measured after 8 hours. On the carton, SARS-CoV-2 was detected after 24 hours and no SARS-CoV-1 was detected after 8 hours. The longest viability of the two viruses was objectified on stainless steel and plastic, the estimated average half-life of SARS-CoV-2 was approximately 5.6 hours on stainless steel and 6.8 hours. on plastic [18].

\section{Other vectors}

The virus can also be found in the stools, conjunctiva and them, these modes of transmission are not excluded but remain rare.

\section{i. The aero-fecal route}

Studies have shown that around 2 to $10 \%$ of confirmed cases of SARS-CoV-2 have been associated with diarrhea. Two studies have reported the detection of residual viral viruses of SARSCoV-2 RNA in the stool of patients with SARS-CoV-2.

However, only one study reported the presence of SARS-CoV-2 in a sample of cultured stools [30-32].

\section{ii. Transmission by wastewater}

In the latest study, the report of the presence of the SARS$\mathrm{CoV}-2$ virus in wastewater was confirmed.

\section{iii. Transmission by insects}

Clinical and laboratory waste of SARS-CoV-2 has been detected in suspect individuals, secretions in the blood (1\%) and faeces (26\%) can also be a major source of virus transmission. But a study has shown the presence of the virus in urine. If this waste is not properly managed, SARS-CoV-2 can be transmitted by insects [33].

\section{Test strategy}

The best strategy to limit the spread of COVID-19 is to identify those infected, isolate them and systematically trace the people with whom they have been in close contact. This very broad approach to testing explains the high number of people screened and a relatively low mortality rate compared to other countries. Thus, the key elements of the strategy for screening and controlling the epidemic are as follows:

i. Rapid identification and isolation of any infected patient.

ii. Identification and quarantine of people who have had high-risk contact with an infected person.

iii. Identification of outbreaks (clusters) of infections in the population and broad screening of these homes [31]. This strategy is in line with the recommendations of the World Health Organization (WHO) and the European Center for Disease Control and Prevention (ECDC).

This identification of people who have already contracted the disease is done by molecular biology and serology tests. 
There are two different types of tests that answer the following two questions:

i. Am I infected and possibly contagious? (diagnostic test).

ii. Have I been sick of COVID-19? (serological test).

These serological tests are marketed by medical analysis laboratories, have no use for the diagnosis of acute infection. These tests are only used to confirm the appearance of acquired immunity (IgA, IgG) at the end of infection, and therefore to make a retroactive diagnosis.

\section{The diagnostic test (qRT-PCR) (quantitative real-time polymerase chain reaction)}

This test answers the question: "Am I infected and am I potentially contagious".

It is based on a swab taken from the nose or mouth, looking for the genetic material of the virus. This test is done on medical prescription. The result is known within 24 hours. The Health Department recommends this test in the following situations:

i. Any patient with symptoms suggestive of COVID-19 infection

ii. All healthcare personnel who have had close contact (less than 2 meters, for at least 15 minutes) without adequate personal protective equipment with a confirmed COVID-19 person. Considering the average incubation period of 5 to 6 days, and the fact that the infected person begins to be contagious 1-2 days before the onset of symptoms, the test is recommended between the 4 th and the 5 th day after the contact. As a precaution the person potentially infected as a result of unprotected contact will always wear a surgical mask at work. Any staff member who becomes symptomatic is immediately dismissed from work and subjected to a test $[26,32]$.

iii. Anyone tested positive for COVID-19, hospitalized or resident in a structure hosting vulnerable people before the isolation is lifted.

iv. Anyone who has died in a hospital or healthcare establishment, whose clinical picture is compatible with COVID-19, without etiological diagnosis, on a sample after death.

The test is not recommended for asymptomatic people who are not professionally active in the health and care system.

Practical procedures for sampling for diagnostic test by RTPCR.

\section{The serological test}

The serological test can help answer the question "Have I been infected with the virus in the past?"

It is in principle not useful for the diagnosis of acute infection but indicates an infection in the past. Serological tests are done with a blood test. The serological tests which will be marketed by medical analysis laboratories in the coming days have no use in the diagnosis of acute infection. These tests only confirm the appearance of acquired immunity (IgA, $\operatorname{IgG}$ ) at the end of the infection and therefore make a retroactive diagnosis [30,32]. They are based on the identification of different antibodies produced during infection. At present, a positive result of a serological test should not be considered as formal proof of immunity and therefore of protection against further infection with the virus.

\section{i. Strategies for using Personal Protective Equipment (PPE) during the SARS-CoV-2 epidemic}

Individual protection measures in health care establishments are usually used to avoid contamination by germs in different care circumstances. These protections prevent staff from colonizing or becoming infected, but also from transmitting germs directly or indirectly via the environment to patients or residents of establishments. In all care situations, precautions are taken, in particular hand hygiene, the hands being the most important vector for the transmission of germs. During respiratory infections, in particular viral, protections are taken to avoid contamination by droplets emitted during coughing or sneezing, or even exhaled air. The new SARS-CoV-2 virus is transmitted primarily by droplets, and airborne transmission is not considered to be significant except when aerosols are produced. However, the absence of aerial transmission has not been demonstrated. Transmission is also facilitated by the contagiousness of carriers with little or no symptoms and the lack of immunity in the population [33]. We recommend a phased strategy for the use of the equipment, according to their availability and the need for protection of each. As soon as the supply situation can be normalized, the capacities being optimal, the usual recommendations apply. These recommendations concern professional dress. It constitutes a means of protection for medical and paramedical personnel. These means of protection are:

A. Protective masks

B. Protective gowns

C. Eye protection

D. Gloves.

\section{A. Protective Masks}

The vigilance of the entire population is required. In the absence of a vaccine or treatment against COVID-19, the adherence of everyone to the health barrier is more important than ever. The World Health Organization (WHO) has paved the way for increased use of masks, including hand-made masks, by the general public in order to limit the spread of the Covid-19 coronavirus. We must reserve medical and surgical masks for frontline staff, but the idea of using masks covering the airways or mouth is to prevent coughing or sniffing from spreading the disease into the environment and to others. . However, there are several varieties of masks: 


\section{i. Alternative masks}

So-called "alternative" or "non-medical" masks can take the form of a homemade cloth mask or a simple cloth covering the mouth and nose. This type of mask helps retain the droplets that are spread when talking, sneezing or coughing [34]. This mask is not suitable for doctors and caregivers, but for the general public in certain situations, including:

i. When you feel sick,

ii. When we want to contribute to the common effort to contain the virus,

iii. In public places where interpersonal distance is difficult to respect.

The virus that causes COVID-19 is capable of being transmitted even if there are no symptoms. It is therefore advisable to cover the mouth and nose with a mask or even with another tissue, especially in public places where interpersonal distance is difficult to respect. Beware, however, of the false sense of security, as there is no scientific evidence to confirm that this mask protects against respiratory viruses.

The French standardization agency (AFNOR) has published a specification and production guide for alternative masks (https:// masques-barrieres.afnor.org) [35].

\section{ii. Surgical masks}

These masks are primarily reserved for doctors and caregivers. They are resistant to fluids and are worn when exposure to droplets or secretions is anticipated, including during surgical procedures. The literature reports that care masks or surgical masks are used to trap droplets of saliva or VAS secretions during the expiration of the person wearing it. It thus prevents the projection of secretions from the upper airways and or salivary which may contain infectious agents transmissible by droplets or by air. They do not protect against contamination with the SARSCoV-2 virus, but they protect others when the person wearing the mask is infected, even without having symptoms. These masks should also be worn by people who are in contact with vulnerable people to protect them [36,37].

\section{iii. Breathing masks}

Respiratory masks called "FFP2" are primarily reserved for doctors and caregivers. They are worn in the event of protection in the context of air transmission. They more effectively protect the caregiver in the event of aerosol production by an infected patient during intubation procedures, nasal or oropharyngeal smears, physiotherapy respiratory care, dental care, opening of the ventilation circuit, endotracheal suction etc. These respiratory masks are standard filter masks (K) N95, EN 149, type FFP2 or FFP3. They more effectively protect the caregiver in the event of aerosol production by an infected patient (intubation procedures, cough with high viral load, in particular if inadequate ventilation in confined spaces). Their re-use is limited (up to 4 hours). It has been shown that $95 \%$ of particles are less than $5 \mu \mathrm{m}$ in diameter, $75 \%$ of which are contaminated with microorganisms. In addition, the particles are concentrated mainly within 2 meters of the patient, where they can easily be inhaled by 13,14 . For these reasons, the use of facial masks in dentistry has been advocated to protect clinicians who inhale aerosols containing organic matter or inorganic particles, and also to protect the patient from possible contamination by the dental operator [38].

A study carried out among nursing staff at Queen Mary Hospital in Hong Kong indicated that wearing a mask is the most important element in protecting against SARS infection, since inhalation of aerosol is the mode of major transmission of this pathology [39]. The effectiveness of respiratory protection masks is different depending on the type and standard of certification. In particular, the standard EN 149: 2001-A1: 2010 (AENOR, 2010), establishes 3 levels of protection according to the degree of leakage of particles towards the interior of the masks. These are FFP1, FFP2, FFP3. The effectiveness of the three types of respiratory protection mask is shown in Table 2 [40]. According to the ADF, the surgical mask or FFp2 must be changed every 4 hours, as well as in the event of soiling or if it becomes wet, with respect for wearing and removal techniques.

Table 2: Efficacy of respiratory protection masks according to the standard, EN 149: 2001-A1: 2010 (AENOR, 2010).

\begin{tabular}{|c|c|}
\hline FFP1 & $22 \%$ \\
\hline FFP2 & $8 \%$ \\
\hline FFP3 & $2 \%$ \\
\hline
\end{tabular}

\section{How to use}

The following rules must be observed when wearing the alternative mask:

a) Position the mask so that it covers the mouth and nose. Attach it carefully to limit the appearance of openings between the face and the mask.

b) Avoid touching your mask while wearing it.

c) When removing the mask, do not touch the front part, but undo it from the back.

d) After touching or removing the mask, wash your hands thoroughly.

e) Wash your mask every day and at a temperature of $60^{\circ} \mathrm{C}$ minimum.

Warning: The mask does not replace the sanitary barrier gestures, the strict application of which remains the most effective measure to curb the spread of the virus $[37,40]$ (Figures $1 \& 2$ ). 


\section{Pose d'un masque chirurgical}
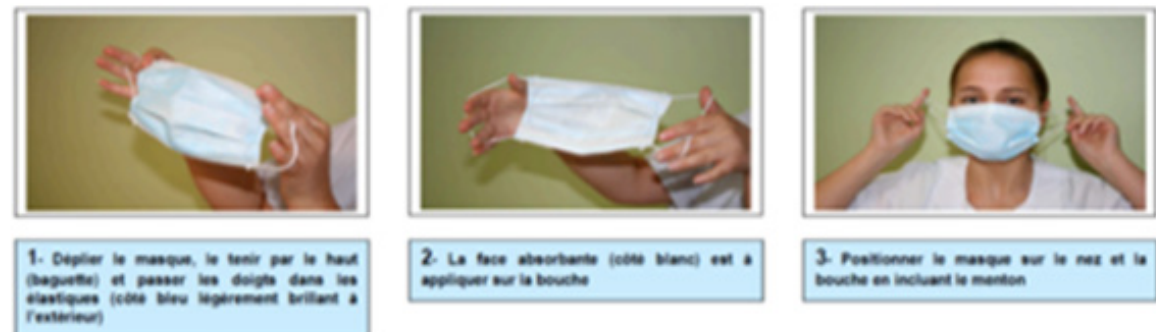

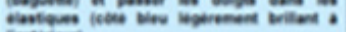
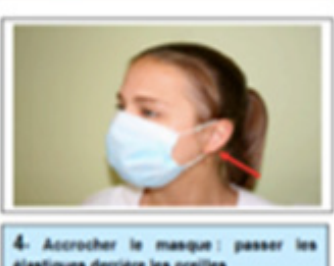

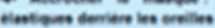

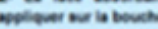

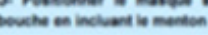
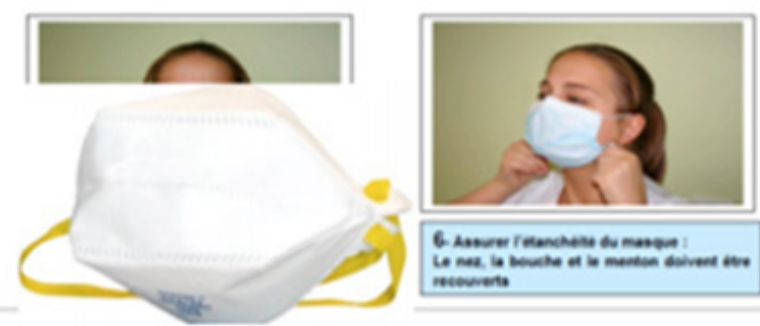

Figure 1: Technique for wearing a surgical type mask [41].

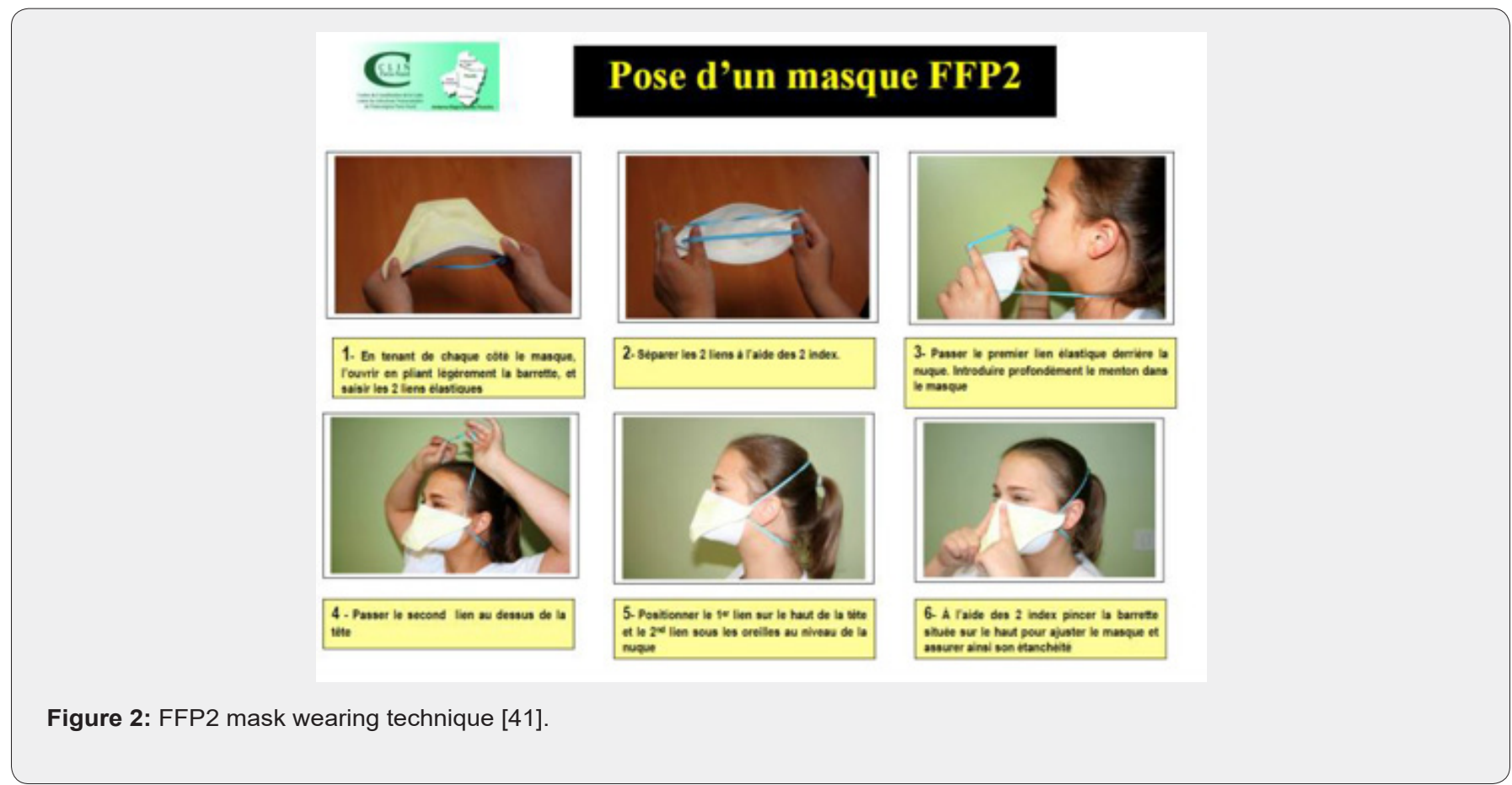

\section{B. Protective gowns}

Non-sterile disposable long-sleeved protective gowns are suitable for the care of COVID patients. One can use non waterproof gowns by adding a plastic apron for acts and care at risk of stains and projection of secretions; alternatively, non-sterile waterproof gowns can be used. Sterile surgical gowns are reserved for surgery and procedures requiring maximum antisepsis. The gowns are to be changed between each patient

\section{Eye protection (visors or protective glasses)}

The use of eye protection is done according to the usual hygiene recommendations and recommended by the producer.
a) Recommend reusable material
i. Protective glasses or face shields: 
ii. Ensure proper cleaning and disinfection between the use of reusable safety glasses or face shields

Eye protection must be changed and replaced if it is visibly soiled or if visibility is reduced.

When reusing single-use eye protection, it must be reserved for the person wearing the protection and changed and replaced if visibly soiled [41].

\section{b) Single use gloves and hand hygiene}

The disposable gloves used for care are non-sterile gloves. It is recommended to use a simple pair of gloves, favor latex-free, powder-free gloves with cuffs.

It is recommended to change gloves:

i. Between two patients,

ii. For the same patient when moving from a contaminated site to a clean site

During care and prior to any hand hygiene:

i. Have the forearms clear,

ii. Have short nails, without varnish, false nails, or resin,

iii. Do not wear jewellery (bracelet, ring, wedding band, watch).

It is recommended to perform hand hygiene:

i. Before contact with the patient,

ii. Before an aseptic gesture,

iii. After a risk of exposure to a biological product of human origin,
iv. After contact with the patient,
v. After contact with the patient's environment

Disinfection by friction with a hydro-alcoholic product is the standard technique in healthcare establishments for all indications of hand hygiene in the absence of visible stains. In the case of visibly soiled hands, simply wash your hands with soap and water. In the absence of gloves, a rigorous hand hygiene is essential and sufficient provided that no area of the hands was forgotten during disinfection $[38,40,41]$.

\section{Health Strategy at the Level of Dental Offices}

At the stage of the epidemic, it is recommended that dental offices apply the following measures:

a) Closure of dental offices at the physical reception of patients.

b) Remote management of relative oral emergencies as much as possible (i.e. not requiring an immediate therapeutic act):

\author{
i. Teleconsultation, \\ ii. Medical advice, \\ iii. Sending a prescription by email
}

c) Management of oral emergencies requiring an urgent therapeutic act (for example: acute irreversible pulpitis, trauma, hemorrhage, etc.) by a practitioner with the necessary personal protective equipment (PPE) (departmental dental office on call).

d) The minimum PPE to take charge of an emergency patient in a city office are: FFP2 mask, protective glasses, cap, on long-sleeved blouse, disposable gloves.

e) Application of strict hygiene measures and adapted barrier measures in offices receiving patients for an urgent therapeutic act.

\section{Risk factors of the profession}

Given the specific characteristics of dental care, the risk of contamination with SARS-CoV-2 between patient and practitioner can be high. Dental surgeons are among the health professionals most exposed to COVID-19. The use of certain materials (rotary, ultrasonic, etc.) generate aerosols (air + high pressure water). Under the effect of the pressure, these aerosols projected into the oral cavity become contaminated (blood, saliva, pulmonary aerosols) and are projected outside the oral cavity. Many dental procedures produce aerosols contaminated with various viruses. The aerosolization of the droplets of saliva contaminates the treatment space (chair, work surfaces, floor, etc.). Certain oral emergencies, in particular painful emergencies (irreversible acute pulpitis.) require an urgent therapeutic act using these materials to relieve the patient. The practitioner must not, by himself or through his professional environment, become a vector of transmission [42-44].

Close communication with a patient, coughing and sneezing also promotes contamination. In addition, dental professionals are at risk of contact with the conjunctival, nasal or oral mucosa and therefore droplets and aerosols containing microorganisms, but also indirect through contaminated dental equipment and instruments or surfaces within the dental office. which is a factor causing the spread of viruses [45]. The surfaces of the cabinet (plastic, metal, wood, glass, walls, etc.) and professional attire (blouses, over-blouses, gowns, hooves, caps, masks, cash hooves, glasses, visors, etc.) constitute the diversity of materials from which they are made a vector for the spread of the virus within the dental office, putting both the staff and the patient at risk. A very large proportion of initial cases of SARS occurred among health care workers, following the presence of factors favoring close and prolonged contact. In Lee's study, of 138 patients studied, 112 were secondary and 26 were tertiary [19]. The patients were divided into 69 caregivers, 16 students and 54 patients hospitalized in the same unit [46-50]. 


\section{Barrier measures linked to care planning}

In stage 3 of the epidemic, given the risk of contamination of the dental surgeon, all patients should be considered potentially infected with SARS-CoV-2 and any symptomatic patient will be considered to be COVID-19 positive.

\section{Closure of offices at the physical reception of patients}

To limit the spread of the virus, dental offices should no longer receive patients on their premises.

\section{Management of urgent oral care}

A. Remote management of the maximum number of emergency situations

i. The dental surgeon treating the patient is the most able to take charge of this type of situation remotely (knowledge of the patient, his medical and dental history, access to previous radiographic examinations, etc.).

ii. Each practitioner must ensure a penalty payment by telephone, by email and must be able to ensure a teleconsultation.

iii. Whenever possible, treatment of the emergency by medical advice and/or sending a prescription by email to the patient or directly to the pharmacy.

iv. Patients receiving a prescription by email must be called back within 48 to 72 hours to ensure the reduction of symptoms.

v. If the practitioner performs a teleconsultation, he must take care to fill in as much as possible the patient's medical file (age, possible comorbidities, treatments in progress, diagnostic elements, absence of criteria of severity, absence of drug allergy).

\section{B. Planning urgent appointments}

If, despite all these measures, medical offices and the health professions are authorized to reopen to the public, in particular to allow care, the suspension of which would lead to a deterioration of the state of health and a loss of chance or quality of life for patients. Care in the dental office can only be done by appointment, except for the care of a patient requiring emergency care.

i. Appointments are scheduled to guarantee a distance of two meters between patients in the waiting room [36].

ii. After entering the waiting room, the patient must have disinfected their hands and be equipped with a mask.

iii. The scheduling of the appointment must consider whether the patient is fragile or not and whether the patient is symptomatic or not.

\section{a) This planning requires:}

Physically isolate symptomatic patients from others:

i. Dedicated waiting room, ii. Waiting outside the cabinet,

iii. Dedicated time slots.

Program fragile patients (aged over 70 or suffering from a chronic pathology) who are not symptomatic at the start of the consultation (in order to limit their exposure to other patients).

Program symptomatic patients at the end of the consultation (each end of half a day).

When planning appointments, you should plan a time of cleaning and ventilation of the office after each appointment (cleaning and disinfection as scrupulous as it is for a sick patient or not) [51].

\section{b) Barrier measurements in the dental office}

\section{i. Protection of dental structure}

Must be cleaned and disinfected at the end of the day:

a) Surface and soil,

b) The office, the examination table (or dental chair) and the office furniture including computer keyboards, telephone, printer.

c) Switches and door handles.

It will also require:

a) Provide a hydro alcoholic solution and protective masks

b) Display practical advice and barrier measures.

c) Display the hydro alcoholic friction protocol.

In the event that a positive Covid-19 patient has been seen in consultation despite screening, it is necessary to ventilate the premises and clean and disinfect all contact surfaces before taking charge of the next patient.

\section{ii. Protection in the waiting room}

Limit the use of the waiting room. It is preferable that the patient enters directly into the treatment room.

Appointments must be organized so as to leave a minimum of two meters between two people in the waiting room (limit the number of seats). After each patient, the waiting room should be ventilated as much as possible. Disinfect at least twice a day and ventilate regularly, for at least 15 minutes. All objects that cannot be disinfected and that are not useful for the care of patients must be removed from the waiting room (remove books, magazines and toys). The furniture must be able to be cleaned and disinfected. There is access to toilets and a place for washing and disinfecting hands. This place is accessible to patients from the waiting room. Limit access to sanitary facilities as much as possible $[21,38]$.

\section{iii. Protection for professionals in charge of reception}

The professional in charge of reception must wear a surgical 
mask. It is protected from patients by a transparent protective screen. He respects the rules of hand washing and applies barrier gestures (maintains a distance of at least one meter with patients). Payment by bank card, electronic payment method or bank transfer are preferred. Wipe bank cards and other means of payment with a disinfectant solution or rub hands with SHA after handling them $[21-38,41]$.

\section{iv. Protection for professionals in charge of care}

Nursing staff who are pregnant or suffering from immunosuppression or who have certain comorbidities (respiratory at risk of decompensation, kidney disease on dialysis, heart failure, cirrhosis of the liver, insulin-dependent or complicated diabetes mellitus) must not be on call. Limit as much as possible the number of nursing staff exposed. Wear a work attire reserved for the care activity. Indeed, the professional follows the rules of hygiene recommended in particular with regard to personal protective equipment (PPE) as well as rules for washing and disinfecting hands. The practitioner must be equipped with the following PPE:

i. Professional attire (including shoes, if not overshoes)

ii. FFP2

iii. Disposable Charlotte

iv. On disposable long sleeve blouse

v. Professional protective glasses

vi. Disposable gloves.

In normal times, you must change the FFP2 mask (when indicated), cap and overcoat between each patient.

In the current context of lack of PPE, it is possible as a temporary solution:

a) To extend the use of a mask for several patients. It is thus possible to do a 4- hour shift with an FFP2 mask.

b) Disposable overcoats and charlottes will be changed, if possible, between each patient.

However, if PPE is contaminated (by blood splashes, saliva, aerosolization...) it must imperatively be changed [21,52-56].

Compliance with basic hygiene rules is essential, before and after each treatment. Hand washing and hydro-alcoholic friction before wearing professional attire is essential. Nail polishes are to be avoided since they constitute a trap for the retention and colonization of germs. The angles must be cut, and the jewelry removed. Studies have shown that washing with soap and water is much less effective than hand disinfection. Washing for several minutes could reduce the flora of the skin. Hand disinfection is indicated in almost all interactions of medical personnel with patients. Thus, the rubbing of hands commonly is considerably more effective than washing them with soap. For example, within 30 seconds of hand disinfection, certain bacteria such as Escherichia coli, Pseudomonas aeruginosa, Staphylococcus aureus or Staphylococcus epidermidis are not only greatly reduced, but almost completely eliminated $[11,57,58]$.

i. Display information on the measures taken vis-à-vis the coronavirus and the techniques of washing and / or friction of the hands.

ii. Make the symptomatic patient wait outside the office or in a dedicated room, especially if other patients are present in the waiting room. Have him wear a surgical mask as soon as he enters the office.

iii. Organize yourself so as not to have several patients present at the same time in the waiting room.

iv. Limit entry only to the patient. For special situations (children, dependent persons, etc.), limit it to one accompanying person.

v. When patients arrive at the office, systematically ask them to wash their hands with soap or to rub their hands with a hydro alcoholic solution (HAS). Ditto for any accompanying persons.

vi. Avoid contact with patients and work colleagues (do not kiss, do not shake hands).

vii. Apart from the act of care, keep a distance of more than one meter between the patient and the practitioner.

viii. Do not touch your face (average frequency of 60 times a day).

ix. Clean screens, keyboards and mobile phones regularly.

x. The equipment used and the surfaces in contact are cleaned and disinfected after each patient.

xi. Condemn the use of spittoons.

xii. Remove all objects and materials present on the work plans.

xiii. At least twice a day as well as at the beginning and end of the consultation

a) Disinfect door handles

b) Air the waiting and treatment rooms for 10 minutes.

\section{Management Protocol}

i. A patient must wear a surgical mask from his arrival at the office and until his departure (leaves with the mask at his home). He only removes it for clinical examination or treatment.

ii. As a precautionary measure, an antiseptic mouthwash must be carried out before any examination or oral care. Before 
starting the treatment, it is recommended to rinse the mouth with a solution of hydrogen peroxide at a concentration of $1 \%$ (the virus is vulnerable to oxidation) or providone at $0.2 \%$ such as betadine before any intervention.

iii. Attention: Chlorhexidine $0.2 \%$ does not effectively destroy the SARS-CoV-2 virus.

iv. The use of a dental dam (Kofferdam) is highly recommended.

v. During treatment, the 4-hand technique as an example is beneficial in controlling the spread [59-61].

\section{Precautions during clinical examination or treatment}

i. Avoid intraoral x-rays which can trigger a cough. Favor a panoramic examination

ii. Avoid other gestures or acts that could make the patient cough

iii. Limit as much as possible the treatments causing aerosolization (limit the use of rotary presses, do not use ultrasound)

iv. Promote the use of a powerful suction, if possible, in combination with a second suction.

v. As soon as possible, use a dike (greatly reduces the projection of saliva droplets)

vi. If a suture is necessary, favor an absorbable thread

vii. In order to limit the practitioner's exposure, stand behind the patient

viii. If a turbine or contra-angle is used: the use of low-speed rotary presses with a minimum water flow rate could reduce the production of droplets and aerosols.

ix. Perform a complete sterilization procedure for the material before reusing it (autoclaving) or use disposable presses (if available) [41,62].

\section{a) In practice, between two meetings}

Keep your FFP2 mask, unless soiled, removed or touched $\rightarrow$ change (for a 4-hour shift).

Change gloves, clean your protective glasses, if possible, change your gown (compulsory if soiled), rub your hands with a hydro alcoholic solution (SHA).

Aerate the treatment room for 10 minutes.

Washing hands with soap or rubbing with an SHA before putting on gloves.

Soiled PPE must be treated as waste from healthcare activities with an infectious risk.

\section{A. Takeover at the Dental Office}

a) For prescriptions

Serious adverse events related to the use of nonsteroidal anti-inflammatory drugs (NSAIDs) and corticosteroids have been reported in patients with COVID-19, possible or confirmed cases. We remind you that the treatment of a badly tolerated fever or pain in the context of COVID-19 or any other respiratory virosis is based on paracetamol, without exceeding the dose of $60 \mathrm{mg} / \mathrm{kg} /$ day and $3 \mathrm{~g} /$ day. NSAIDs should be banned [16]. In case of severe pain, it is possible, in the absence of allergy, to prescribe morphine derivatives (codeine, tramadol) [22,40].

\section{B. CAT if the patient is sick}

If the practitioner presents symptoms suggestive of COVID-19, it must:

a) Stop working.

b) Get tested for COVID-19 (RT-PCR test). Health professionals are tested so as not to be a source of transmission themselves. Depending on the territory, the sample is taken in town and / or at the hospital.

Depending on the result of the RT-PCR and the clinical state of the practitioner, an activity protocol will be decided with the attending physician (cessation of all activity, reception and sorting of patients with suitable PPE, urgent care provided with PPE adapted...) [62].

\section{Conclusion}

Despite the high practical and theoretical data, dentists around the world are in a state of anxiety and fear in the face of this pandemic which is impacting humanity. Currently, strict adherence to hygienic and aseptic measures and the scheduling of selective care is the only way to minimize the risk of SARS-Cov2 nosocomial infections occurring in the dental office. Still, dental professionals must remain vigilant in the face of this pandemic as long as diagnostic tests are not yet available to them and thus consider any patient as being an asymptomatic carrier until proven otherwise.

\section{References}

1. Ge ZY, Yang LM, Xia JJ, Fu XH, Zhang YZ (2020) Possible aerosol transmission of COVID-19 and special precautions in dentistry. J Zhejiang Univ Sci B 16: 1-8.

2. Chen J (2020) Pathogenicity and transmissibility of 2019-nCoV-a quick overview and comparison with other emerging viruses. Microb Infect 22(2): 69-71.

3. Fehr AR, Perlman S (2015) Coronaviruses: an overview of their replication and pathogenesis. In Coronaviruses. Humana Press, New York, USA, p. 1-23.

4. Gorbalenya AE, Enjuanes L, Ziebuhr J, Snijder EJ (2006) Nidovirales: evolving the largest RNA virus genome. Virus Res 117(1): 17-37. 


\section{Advances in Dentistry \& Oral Health}

5. Fan Y, Zhao K, Shi ZL, Zhou P (2019) Bat Coronaviruses in China. Viruses 11(3): 210.

6. Perlman S, Netland J (2009) Coronaviruses post-SARS: update on replication and pathogenesis. Nat Rev Microbiol 7(6): 439-450.

7. Marra MA, Jones SJ, Astell CR, (2003) The genome sequence of the SRAS associated coronavirus. Science 300: 1399-1404.

8. Organisation Mondiale de la Santé (2020).

9. Santé publique France. Infection au nouveau Coronavirus (SARS CoV-2), COVID-19, France et monde. (2020) www.santepubliquefrance. fr Consulté le 19 mars 2020

10. Haut Conseil de la Santé Publique (2020). Avis relatif à la prise en charge des cas confirmés d'infection au virus SARS-CoV-2.5.

11. Haut Conseil de la Santé Publique (2020). Avis relatif au traitement du linge, au nettoyage d'un logement ou de la chambre d'hospitalisation d'un patient confirmé à SARS-CoV-2 et à la protection des personnes.

12. Rothe C, Schunk M, Sothmann P (2020) Transmission of 2019-nCoV Infection from an Asymptomatic Contact in Germany. N Engl J Med 382(10): 970-971.

13. Marra MA, Jones SJ, Astell CR (2003) The genome sequence of the SRASassociated coronavirus. Science 300: 1399-1404.

14. Lu R, Zhao X (2020) Genomic characterisation and epidemiology of 2019 novel coronavirus: implications for virus origins and receptor binding. The Lancet 395(10224): 565-574.

15. Roser M, Ritchie H (2020) Coronavirus Disease (COVID-19). Our World.

16. Situation Report-22 Novel Coronavirus (2019-nCoV).

17. (2020) Novel Coronavirus (2019-nCoV) Situation Report - 22 (World Health Organization, 2020).

18. N van Doremalen (2020) Aerosol and Surface Stability of SARS-CoV-2 as Compared with SARS-CoV-1. New England Journal of Medicine.

19. Report of the WHO-China Joint Mission on Coronavirus Disease 2019 (COVID-19)

20. (2020) World Health Organization. Modes of transmission of virus causing COVID-19: implications for IPC precaution recommendations. Scientific brief.

21. Woelfel R, Corman VM (2020) Clinical presentation and virological assessment of hospitalized cases of coronavirus disease 2019 in a travel-associated transmission cluster. Med Rxiv.

22. Lu CW, Liu XF, Jia ZF (2020) 2019-nCoV transmission through the ocular surface must not be ignored. The Lancet 6736(20)30313-30315.

23. (2020) Société Française d'Hygiène Hospitalière. Avis relatif aux conditions de prolongations du port ou de réutilisation des masques chirurgicaux et des appareils de protection respiratoire de type FFP2 pour les professionnels de santé.

24. Meng L, Hua F, Bian Z Coronavirus Disease 2019 (COVID-19): Emerging and Future Challenges for Dental and Oral Medicine Journal of Denta Research 1- (C) International \& American Associations for Dental Research.

25. Hadi Eslami, Mahrokh Jalili (2020) The role of environmental factors to transmission of SARS-CoV-2 (COVID-19).

26. (2020) Centre for Health Protection. Severe respiratory disease associated with a novel infectious agent-letters to doctors.

27. Sri Santosh, Reshu Parmar, Hanish Anand, Konkati Srikanth, Madham Sarith (2020) A Review of Salivary Diagnostics and Its Potentia Implication in Detection of Covid- 19 Tatikonda.
28. Kampf G, Todt D, Pfaender S, Steinmann E (2020) Persistence of coronaviruses on inanimate surfaces and its inactivation with biocidal agents. J Hosp Infect 104(3): 246-251.

29. Otter JA (2016) Transmission of SARS and MERS coronaviruses and influenza virus in healthcare settings: the possible role of dry surface contamination. J Hosp Infect 92: 235-250

30. Wang D, Hu B, Hu C, (2020) Clinical characteristics of 138 hospitalized patients with 2019 novel coronavirus-infected pneumonia in Wuhan China. JAMA 323: 1061-1069.

31. Xiao F, Tang M, Zheng X, Li C, He J, et al. (2020) Evidence for gastrointestinal infection of SARS-CoV-2. Med Rxiv.

32. (OMS 2020).

33. Chang L, Yan Y, Wang L (2020) Coronavirus disease 2019: coronaviruses and blood safety. Transfus Med Rev 34(2): 75-80.

34. https://www.nature.com/articles/d41586-020-00974-w

35. Long Y, Hu T, Liu L, Chen R, Guo Q et al. (2020) 505 Effectiveness of N95 respirators versus surgical masks against influenza: A systematic review and meta-analysis. J Evid Based Med 13(2): 93-101.

36. Seto WH, Tsang D, Yung R (2003) Effectiveness of precautions against droplets and contact in prevention of nosocomial transmission of severe acute respiratory syndrome (SRAS). Lancet 361: 1519-1520.

37. Mariachiara Ippolito, Filippo Vitale, Giuseppe Accurso, Pasquale Iozzo, Cesare Gregoretti, et al. (2020) Medical Masks and Respirators for the Protection of Healthcare Workers From SARS-CoV-2 and Other Viruses Affiliations expand PMID: 32362505.

38. Luigi Checchi, Marco Montevecchi, Annalisa Moreschi, Francesca Graziosi, Paola Taddei et al. () Efficacy of three face masks in preventing inhalation of airborne contaminants in dental practice. JADA 136(7): 877-882.

39. Disposable masks: Disinfection and sterilization for reuse, and noncertified manufacturing, in the face of shortages during the COVID-19 pandemic Juan Carlos Rubio-Romero, María del Carmen PardoFerreira, Juan Antonio Torrecilla García, and Santiago Calero-Castro.

40. http://medcomip.fr/--82/tg-infectiologie/170427-utilisation-desmasques.

41. Li R, Pei S, Chen B, Song Y, Zhang T, et al. (2020) Substantial undocumented infection facilitates the rapid dissemination of novel coronavirus (SARS-CoV2). Science 368: 489-493.

42. Wang D, Hu B, Hu C, Zhu F, Liu X, et al. (2020) Clinical Characteristics of 138 Hospitalized Patients With 2019 Novel Coronavirus- Infected Pneumonia in Wuhan, China. JAMA 323(11): 1061.

43. Xian Peng, Xin Xu, Yuqing Li, Lei Cheng, Xuedong Zhou, et al. (2020) Transmission routes of 2019-ncov and controls: in dental practice international journal of oral science 12:9.

44. Jennifer L Cleveland, Shellie Kolavic Gray, Jennifer A Harte, Valerie A Robison, Anne C Moorman, et al. (2016) Transmission of blood-borne pathogens in US dental health care settings: 2016 update. J. Am Dent Assoc 147(9): 729-738.

45. Lee N, Hui D, Wu A, Chan P, Cameron P, et al. (2003) A Major Outbreak of Severe Acute Respiratory Syndrome in Hong Kong. N Engl J Med 348:1986-1994

46. Meng L, Hua F, Bian Z (2020) Coronavirus Disease 2019 (COVID-19): Emerging and Future Challenges for Dental and Oral Medicine. Journal of Dental Research 99: 5.

47. Peng X, Xu X, Li Y (2020) Transmission routes of 2019-nCoV and controls in dental practice. Int J Oral Sci 12: 9. 
48. Gamio L (2020) The workers who face the greatest coronavirus risk. The New York Times.

49. Wei J, Li Y (2016) Airborne spread of infectious agents in the indoor environment. Am J Infect Control 44(9): S102-S108.

50. Ministère des solidarités et de la santé (2020). Prise en charge des patients Covid-19 en ville. Version du.

51. Hand Hygiene for the Prevention of Nosocomial Infections Günter Kampf, Harald Löffler, Petra Gastmeier Deutsches (2009) Ärzteblatt International. Dtsch Arztebl Int 106(40): 649-655.

52. Weber DJ, Sickbert-Bennett E, Gergen MF, Rutala WA (2003) Efficacy of selected hand hygiene agents used to remove Bacillus atrophaeus (a surrogate of Bacillus anthracis) from contaminated hands. The Journal of the American Medical Association 289: 1274-1277.

53. Robert Koch (2000) Institut: Händehygiene. Bundesgesundheitsblatt 43: 230-233.

54. WHO: WHO guidelines on hand hygiene in health care? First global patient safety challenge-clean care is safer care (2009). Geneva: WHO.

55. Kampf G, Löffler H, (2009) Hand Hygiene for the Prevention of Nosocomial Infections Günter. Petra Gastmeier Deutsches Ärzteblatt International | Dtsch Arztebl Int 106(40): 649-655.
56. Société Française d'Hygiène Hospitalière (2020). Avis relatif aux conditions de prolongations du port ou de réutilisation des masques chirurgicaux et des appareils de protection respiratoire de type FFP2 pour les professionnels de santé.

57. American Dental Association. ADA Coronavirus (COVID-19) Center for Dentists.

58. Société Française de Médecine du Travail. Avis relatif à l'éviction des personnels de soins. 10 mars 2020

59. Samaranayake (2004) Peiris.

60. Meng L, Hua F, Bian Z (2020) Coronavirus Disease 2019 (COVID-19): Emerging and Future Challenges for Dental and Oral Medicine. Journal of Dental Research.

61. Recommandations d'experts portant sur la prise en charge en réanimation des patients en période d'épidémie à SARS-CoV2. SRLFSFAR-SFMU-GFRUP-SPILF. Mise en œuvre avec la mission COREB nationale (2020).

62. Haut Conseil de la Santé Publique. Recommandations s'agissant de la priorisation des tests diagnostiques du COVID-19.10 (2020).

\begin{tabular}{l} 
Your next submission with Juniper Publishers \\
will reach you the below assets \\
- Quality Editorial service \\
- Swift Peer Review \\
- Reprints availability \\
- E-prints Service \\
- Manuscript Podcast for convenient understanding \\
- Global attainment for your research \\
- Manuscript accessibility in different formats \\
( Pdf, E-pub, Full Text, Audio) \\
- Unceasing customer service \\
Track the below URL for one-step submission \\
https://juniperpublishers.com/online-submission.php \\
\hline
\end{tabular}

